\title{
Metamorfose do mundo: um ponto de inflexão na história da humanidade?
}

\author{
The metamorphosis of the world: a turning point in human history? \\ Metamorfosis del mundo: ¿un punto de inflexión en la historia humana?
}

Eduardo Teixeira de Carvalho Jr*

Beck, Ulrich. A metamorfose do mundo: novos conceitos para uma nova realidade. Tradução de Maria Luiza X. de A. Borges. Rio de Janeiro: Zahar, 2018. 259p.

O diálogo com sociólogos como Jürgen Habermas e Pierre Bourdieu ampliaram os horizontes da História e levaram a produçóes fundamentais dentro da historiografia. Contudo, parece que o trabalho de Ulrich Beck ainda não foi devidamente apreciado pelos historiadores. A metamorfose do mundo: novos conceitos para uma nova realidade pode ser uma oportunidade interessante para se aproximar de sua teoria social, além disso, é um diagnóstico histórico ambicioso sobre as transformaçóes do mundo contemporâneo.

Ulrich Beck foi professor de sociologia na Universidade de Munique, na London School of Economic's and Political Science e doutor honoris causa por diversas univer- sidades europeias. As preocupaçôes e questôes desenvolvidas no conjunto de sua obra o colocam ao lado dos grandes intérpretes da modernidade, como o próprio Jürgen Habermas, Michel Foucault e Zygmunt Bauman. Beck tornou-se conhecido após a publicação de Risikogesellshaft (1986), traduzido para o português com o título Sociedade de risco: rumo a uma outra modernidade (BECK, 2011). Esse livro foi publicado no mesmo ano em que ocorreu o acidente nuclear de Chernobyl, as incertezas e o sentimento de falta de controle em relaçáo ao uso da energia nuclear apresentavam uma impressionante coincidência com as análises desenvolvidas por Beck.

Já o livro objeto desta resenha é uma obra inacabada, interrompida pela sua morte repentina em 2015. O texto foi finalizado com a ajuda de alguns pesquisadores e principalmente a socióloga Elisabeth Beck-Gernsheim, esposa e coautora de livros de

DOI: http://dx.doi.org/10.1590/2237-101X02204816

Resenha recebida em 4 de agosto de 2020 e aceita para publicação em 30 de setembro de 2020.

* Professor do Centro Universitário Curitiba, Curitiba/ PR - Brasil. E-mail: eduardotcjr@gmail.com. ORCID: https://orcid.org/0000-0002-5926-1411. 
Ulrich Beck. Conforme apontado por ela no prólogo, foi um grande desafio "elucidar e revisar frases incompletas, parágrafos que terminavam abruptamente e texto (escrito em inglês) que soava muito alemão" (p. 10).

O livro é dividido em três partes, a primeira traz uma discussão teórica sobre o conceito de metamorfose, a segunda discute como sua teoria da metamorfose pode nos ajudar a compreender determinados eventos que estão ocorrendo no mundo atual, e, por fim, a terceira parte traz um ensaio geral como tentativa de uma conclusão.

$\mathrm{O}$ conceito de metamorfose, conceito-chave que perpassa todo o livro, possui um duplo sentido. Metamorfose indica um processo de profunda transformação na história da humanidade e ao mesmo tempo a necessidade de uma metamorfose da teoria social que possa captar essa transformação. Fazendo referência a Thomas Kuhn (1997), propóe um novo paradigma, uma virada copernicana no campo das ciências sociais. Conforme trabalhos anteriores (BECK, 1999), Beck critica o "nacionalismo metodológico" e propóe o "cosmopolitismo metodológico", ou seja, uma abordagem que vá além das fronteiras nacionais. Não se trata mais de um mundo moldado pelos estados nacionais, mas as naçóes girando em torno do mundo. Para ele já superamos o período de idealização da globalização e entramos em uma nova etapa histórica, marcada por um realismo global ao qual todos nós estamos sujeitos independentemente de nossas vontades. A mudança climática está transformando a geografia do mundo, ela pode levar à seca uma determinada região e a no- vos vinhedos em outra. Esse processo abre um campo novo de açóes não previstas, o que ele chama de "espaços de ação cosmopolizados", que são espaços de ação não institucionalizados num enquadramento nacional, oportunidades abertas de ação que não estão sujeitas à lógica da reprodução social, mas à lógica da metamorfose. A indústria da reprodução biológica humana, por exemplo, opera globalmente e contorna os impedimentos jurídicos nacionais, assim, casais alemães contratam serviços de barriga de aluguel na Índia. Surgem categorias sociais de parentalidade historicamente novas como "mães sociais que encomendam e compram um filho", "doadores de esperma”, "doadoras de óvulos", "barrigas de aluguel”, “mães sem pai", "pais sem mãe".

O uso da palavra metamorfose no lugar de mudança parte do princípio de que a mudança é uma palavra típica da modernidade, caracterizada pela mudança permanente, enquanto os conceitos básicos e as certezas que a sustentam permanecem constantes. Um dos princípios que norteiam a sua proposta metodológica é o que ele chama de "destradicionalização das formas de vida". Trata-se de uma transformação social no interior da modernidade, processo em que as pessoas são libertadas das formas sociais da sociedade industrial (classe, estrato, família, estatutos de gênero para homens e mulheres), abrindo um novo campo de formação de identidades e de açôes sociais. Dessa forma, sua teoria da metamorfose também consiste em uma proposta de superação das abordagens convencionais, a exemplo de Foucault e Pierre Bourdieu, que se concentram mais na mudança 
social dentro da estrutura de reprodução da ordem social e política. De acordo com Beck, como o enfoque dessas teorias não está na transformação, não conseguem captar a metamorfose. Por isso declara que a "história está de volta!". Rejeita termos como "revolução", "evolução", "transformação", essas palavras servem para dar conta de processos que em parte das estruturas se alteram, mas outras permanecem. Contudo, "a metamorfose implica uma transformação muito mais radical, em que as velhas certezas da sociedade moderna estáo desaparecendo e algo inteiramente novo emerge" (p. 15).

Ao longo do livro, Beck retoma alguns princípios de sua teoria da sociedade de risco (BECK, 2011) para tornar mais clara sua nova proposta teórica, a teoria da metamorfose. $\mathrm{O}$ conceito de sociedade de risco pode ser compreendido na maneira como Beck se insere nos debates sobre a modernidade. Por uma perspectiva singular, Beck chama atenção para o fato de que um dos traços marcantes da modernidade é a exaltação das vantagens do progresso científico na mesma medida em que são mitigados seus efeitos colaterais. $\mathrm{O}$ processo de industrialização segue o princípio "in dúbio pro progresso", ou seja, na dúvida, preferimos o progresso, e assim vivemos em uma civilização em que o risco é natural e legitimado (BECK, 2011, p. 41). Beck ressalta que o reconhecimento sobre os riscos e ameaças da sociedade industrial somente se impôs depois de muita negação e resistência sob o manto de uma racionalidade científica satisfeita consigo mesma e comprometida com a crença no progresso (BECK, 2011, p. 70). Os riscos na moderni- dade se diferenciam de outras épocas de sua historia pelo seu caráter de fabricação, não são naturais, mas fruto de consequência imediata das sociedades industriais modernas. Diferentemente de erupções vulcânicas ou tsunamis, existem catástrofes que são produto da ação do homem e implicam a questão da responsabilidade. $\mathrm{O}$ risco na perspectiva de Beck é de um tipo fabricado, que poderia ou deveria ser dimensionado, mas não o é adequadamente por motivos complexos, gerando o que Beck chama de "irresponsabilidade organizada". Conforme aponta Julia Guivant, "Para Beck os riscos não são sinônimo de catástrofe, mas sim a antecipação desta" (GUIVANT, 2016, p. 230).

Assim, o conceito de "sociedade de risco" pode ser compreendido como uma nova fase da modernidade em que os valores perseguidos pelas sociedades industriais modernas (renda, empregos, seguridade social) passam a ser contrabalançados pelos males intrinsecamente decorrentes do projeto da modernidade. Riscos globais como radiação e mudanças climáticas não são percebidos como evidências sensoriais, há uma invisibilidade natural na maneira como esses fenômenos se manifestam. A estratégia de invisibilidade é uma estratégia importante para manter a estabilidade e autoridade dos Estados, que muitas vezes negam ou minimizam a existência dos riscos e seus efeitos negativos para determinados segmentos populacionais, como aconteceu no acidente de Chernobyl (1986). A indústria do tabaco, por exemplo, trabalhou para tornar invisíveis os efeitos do fumo para a saúde. Outro exemplo, em 2015 ocorreu o que vem sendo 
considerada a maior tragédia ambiental da história do Brasil, o rompimento da barragem de rejeitos Fundáo, localizada na cidade de Mariana (MG), e mais tarde na Mina do Feijão, no município de Brumadinho (MG). Depois de uma investigação preliminar, mediante a análise de relatórios técnicos, chegou-se à conclusão de que as duas catástrofes poderiam ter sido evitadas.

Com os efeitos dessas catástrofes surge uma nova categoria social: "classe de risco". Os que sofrem os efeitos colaterais dos males da sociedade capitalista global sofrem uma dupla exclusão, são excluídos dos benefícios potenciais das decisóes e das condiçóes sob as quais a decisão é tomada, e, além disso, são excluídos da formulação das regulaçôes e efeitos jurídicos de responsabilidade. Nesse sentido, aumenta a necessidade e a importância social e política do conhecimento e sua publicização (opinião pública). Essas questôes levam-no a se preocupar com uma outra sociologia do conhecimento e póem em questão o monopólio pretendido pela ciência, e, sobretudo dos especialistas, sobre a percepção do risco.

A sociologia convencional concentra-se na distribuição de bens (renda, educação, saúde, prosperidade, previdência social). A sociedade de risco mundial baseia-se na distribuição de males (risco climático, risco financeiro, radiação nuclear). A teoria da metamorfose enfoca as duas, distribuição de bens e males. Para Beck, a teoria convencional ignora as novas formas de desigualdade produzidas pela globalização. $\mathrm{O}$ processo concomitante de progresso e inovação e distribuição de bens forjados pela moderni- dade deve ser pensado juntamente com a questão da distribuiçáo de males, que, embora se desenvolvam em direçóes opostas, estão interligados. A metamorfose é a síntese desses dois processos:

Esta interligação é produzida através não do fracasso do processo de modernização ou através de crises, mas de seu próprio sucesso. Quanto mais bem-sucedido ele é, mais simples ele é, mais males são produzidos. Quanto mais a produção de males é ignorada e menosprezada como dano colateral do processo de modernizaçáo, maiores e mais poderosos os males se tornam (p. 94).

$\mathrm{Na}$ segunda parte do livro, Beck procura ampliar a análise da metamorfose a partir do aprofundamento de algumas questóes trabalhadas na primeira parte e apresenta uma discussão sobre alguns conceitos como o de "catastrofismo emancipatório", um dos mais interessantes tratados no livro. Paradoxalmente, "catastrofismo emancipatório" indica o lado positivo dos males, que, segundo Beck, criam um novo horizonte de expectativa. Olhando em perspectiva histórica, Beck cita o exemplo da Segunda Guerra Mundial como um marco exemplar do que ele chama de "catastrofismo emancipatório". O horror dessa experiência histórica levou à criação de uma série de instituições cosmopolitas como a ONU, o FMI, o Banco Mundial. É a violaçấo que cria a norma, e não o contrário. Por exemplo, embora fosse legal sob a lei nazista matar judeus, isso acabou se tornando um crime contra a humanidade. 
Não foi simplesmente uma lei que mudou, mas nossos horizontes sociais, nossa forma de estar no mundo.

Para Beck, embora carregadas de consequências negativas, as catástrofes libertam um impulso humanitário, pois violam valores sagrados da existência da civilização humana causando um choque antropológico geralmente acompanhado por uma catarse social. Depois das catástrofes surgem novas leis, um novo ordenamento jurídico, novas tecnologias. "Foi o 'choque antropológico' decorrente da catástrofe de Chernobyl como um evento de mídia que tornou visível a invisibilidade do risco da radiação" (p. 132). Aqueles que são atingidos dependem dos meios científicos e administrativos de visibilidade, o que implica a questão da "democratização do risco", o acesso em relação ao seu poder de definição. Uma série de instituiçóes foram criadas para limitar o poder do capital e proteger os trabalhadores, como sindicatos, estado de bem-estar social, leis trabalhistas. Contudo, pouco foi feito em relação à definição de risco mundial. As normas de responsabilidades são insuficientes. Os movimentos reivindicatórios por justiça estáo sendo expressos de forma global. Vai se construindo uma esfera pública global, um debate público diferente daquele circunscrito na perspectiva nacional e que amplia os fundamentos filosóficos do imaginário jurídico ocidental. Para Beck, os riscos globais estáo provocando uma revolução antropológica sobre as formas de estar no mundo.

$\mathrm{Na}$ metamorfose, a sociedade mundial tornou-se produto da comunicação digital.
Não são os eventos catastróficos por si só, mas as imagens globalizadas desses eventos que desencadeiam o choque antropológico que fornece o enquadramento normativo para uma ética do "nunca mais". Por isso, mudança climática não é simplesmente mudança climática, é mais que uma alteração nas dinâmicas de temperatura da terra, é uma reforma nas formas de pensar, de estilos de vida e hábitos de consumo, direito de futuras geraçôes, é o reflexo de uma nova forma de estar no mundo. Sáo as imagens que liberam a emoção e a identificação com o sofrimento do outro que desencadeia o choque antropológico. Não é a catástrofe em si, mas sua representação que libera o potencial emancipatório. Isso tudo reflete o fim dos sistemas nacionais de comunicação e a existência comunicativa de "todo mundo com todo mundo".

$\mathrm{Na}$ terceira parte do livro, um ensaio de caráter conclusivo, Beck aponta para um choque entre uma geração marcada por uma visão de mundo nacional e outra marcada pelo ímpeto da perspectiva cosmopolita. $\mathrm{Na}$ metamorfose, os jovens nativos digitais sabem mais do que seus pais, a geração mais jovem se torna mestra da mais velha. O homo cosmopoliticus é produto da metamorfose, enquanto a geraçấo mais velha experimenta a metamorfose como uma ameaça a sua existência. Os idosos nasceram como seres humanos, mas como no romance de Kafka, acordaram em uma manhá como insetos chamados "analfabetos digitais" (p. 242). Já os mais jovens nascem seres digitais, ser digital é parte de sua bagagem genética. A relação entre pai e filho é alterada, assim 
como entre professor e aluno. Isso significa que as geraçóes mais velhas e as mais novas são contemporâneas, mas não vivem no mesmo tempo. Conforme aponta Beck:

[...] o arranjo e os contornos das posiçóes desiguais (como classes, naçóes, centro e periferia) são inadequados para representar a desigualdade das posiçóes das geraçóes de risco no início do século XXI; novas posiçóes ainda não estáo à vista ou não foram empiricamente testadas (p. 247).

Há uma expectativa global de igualdade. Os conflitos apenas surgem quando novas expectativas sociais de igualdade (especialmente direitos humanos) se espalham. Assim, a desigualdade já não é mais compreendida como um destino, como algo inexorável, mas colocada em questão. Os excluídos, habitantes de lugares onde a vida é precária e insegura, começam a se rebelar através da esperança de sonhos de migração. Paradoxalmente, em muitos países do mundo, a geração mais educada historicamente enfrenta o problema do desemprego estrutural: "o graduado sem futuro da geração precarité" (p. 250). Dessa forma, emerge uma nova luta pela redistribuiçáo global dos males e dos benefícios, um lado na defensiva, tentando se agarrar ao bem-estar cercado pelas fronteiras nacionais, e outros forçando essas barreiras movidos pela esperança de uma vida melhor. Vivemos um momento histórico em que as desigualdades nacionais vêm encontrando dificuldades para serem legitimadas. Trata-se de um grande problema, pois as desigualdades também conti- nuam a crescer nos contextos nacionais e os recursos que poderiam amenizar seus efeitos estão sendo abolidos.

Rompendo com o enquadramento nacional, os males globais só podem ser visíveis dentro do enquadramento cosmopolita. A dificuldade de se renomear certas categorias por meio de um novo vocabulário é bastante perceptível ao longo do livro, e Beck nos lembra a todo o momento que tem ciência de estar entrando em um território desconhecido. A metamorfose é um esforço em desenvolver uma nova teoria social que vá além da "sociedade de risco". Os neologismos utilizados revelam a tentativa de expandir o campo linguístico na direção de novos conceitos, como no caso de "espaços" para "espaços cosmopolizados", "catástrofe" para "catastrofismo emancipatório", "classe" para "classe de risco".

Os conceitos e questóes levantadas por Beck ao longo do livro carecem de mais estudos concretos para que possam ganhar mais consistência. Contudo, isso não enfraquece o argumento do livro, cujo valor principal consiste mais nas perguntas levantadas do que nas respostas oferecidas. $A$ metamorfose do mundo: novos conceitos para uma nova realidade é uma obra fundamental para quem quer compreender o processo de transição histórica que estamos vivendo. A metamorfose não expressa nem otimismo nem pessimismo sobre o curso da história. Não aponta para o declínio do Ocidente ou de que as coisas vão melhorar, mas sim, abre espaço para um campo novo de decisóes políticas desafiando nosso modo de estar no mundo e de pensar sobre o mundo. 


\section{Referências}

BECK, Ulrich. O que é globalização? Equívocos do globalismo, respostas à globalização. Rio de Janeiro: Paz e Terra, 1999.

BECK, Ulrich. Sociedade de risco: rumo a uma outra modernidade. São Paulo: Editora 34, 2011.
BECK, Ulrich. A metamorfose do mundo: novos conceitos para uma nova realidade. Tradução de Maria Luiza X. de A. Borges. Rio de Janeiro: Zahar, 2018.

GUIVANT, Julia Silvia. O legado de Ulrich Beck. Ambiente \& Sociedade, São Paulo, v. XIX, n.1, p. 229-240, jan./mar. 2016.

KUHN, Thomas S. A estrutura das revoluçóes cientificas. 5. ed. São Paulo: Editora Perspectiva, 1997. 